\title{
Rayleigh's Public Lectures with Acoustical Experiments
}

\author{
Ja Hyon Ku \\ University College of Undeclared Majors, Youngsan University \\ (Received May 30, 2011; accepted July 29, 2011)
}

\begin{abstract}
From 1860s to 1910s, Rayleigh's efforts to reveal the nature and various features of sound continued to achieve good success in theory and experiment. Although his concern with acoustics primarily originated from intellectual curiosity, he did not ignore its practicality. His efforts were made to develop public lectures with demonstration experiments during his professorship at the Royal Institution of Great Britain. Acoustics covered the second-most frequent subject in his public lectures and his acoustical experiments were designed for satisfying the needs of the audience by employing ingenious strategies.
\end{abstract}

Keywords: Rayleigh, Practicality, Demonstration, Royal Institution, Public Lecture, Experiment

Subject classification: General Area (0.1)

\section{Introduction}

The 3rd Baron Rayleigh (John William Strutt, 1842-1919), one of the most influential scientists in the late nineteenth and early twentieth centuries in Great Britain, won the Nobel Prize in Physics in 1904. He is also famous for his treatise, The Theory of Sound (1877-78), which is credited with opening up modern acoustics and contributing to the development of mathematical physics [1]. He was instrumental in developing the Cavendish Laboratory into an established center of experimental physics under his leadership from 1880 to 1884 [2]. Following his resignation from the Laboratory, his research was conducted chiefly at his own home in Terling Place, Essex. Although he was interested in a variety of subjects, his most extensive research was conducted in acoustics.

Corresponding author: Ja Hyon Ku (taramdge@hotmail.com) University College, Youngsan University, Junam-dong, Yangsan, Gyeongnam 626-790 Republic of Korea

(Tel: +82-51-900-2185)
Among around 450 research papers that he wrote during his long career, 130 papers or so were primarily related to acoustics [3]. He was a leader in both mathematical and experimental acoustics throughout his career. Through this work, he established acoustics as a subfield of physics by amalgamating an empirical enterprise on sound with speculative mathematical endeavors mainly involving differential equations.

Traditionally the experimental researches on sound were chiefly motivated by practical purposes. During the eighteenth and the nineteenth centuries important advances in acoustical research were achieved by musical theorists and musical instrument makers [4]. As for Rayleigh, practicality was not his main motive for performing acoustical research. His primary interest in science research including acoustics was in revealing the hidden order of nature. Nevertheless, he was sometimes interested in the application of his acoustical expertise to practical problems. In particular he applied his know-how to designing and carrying 
out public demonstration lectures at the Royal Institution of Great Britain.

The present paper will provide examples of how the influential acoustician in the late nineteenth and early twentieth centuries designed demonstration lectures by applying his knowledge of sound to public lectures. In this course it will analyze the demonstration experiments in terms of the publication of private acts and the visualization of sound. This will show how useful Rayleigh's acoustical experiments were for fulfilling the purpose of enhancing public understanding of science.

\section{Rayleigh's Public Lectures}

Public lectures on science have a quite long history in British society. They were enjoyed as an element of British culture since the eighteenth century [5]. For the people who had considerable wealth and social status, listening to science lectures was a cultural activity like going to concerts and visiting galleries. Scientists wished to earn support for research as well as to contribute to society through the popularization of science and the transmission of information about scientific phenomena to the public. By showing their research ability and arousing the interest of possible supporters, scientists would get financial support for their work.

Public lectures for this purpose had to reflect fresh results of recent research and include contents understandable and interesting to a public audience. It was natural that demonstration experiments providing magnificent sights should constitute a salient element in the public lectures. So demonstration experiments in public lectures were supposed to provoke the interest and curiosity of the audience. Able lecturers carefully selected experiments having this feature and investigated how to demonstrate those experiments effectively.

When Charles Taylor, the author of the book The Art and Science of Lecture Demonstration, introduces the demonstration experiments in the nineteenth century, he does not mention Rayleigh's experiments, though he gave a detailed explanation of John Tyndall's sensitive flame and singing flame. While he treats demonstration experiments with sound, he refers only to Hermann Helmholtz, Rudolph Koenig, and D.C. Miller, omitting Rayleigh, a more successful demonstrator than any of them [6].

Rayleigh's demonstration experiments were carried out while he was the Professor of Natural Philosophy at the Royal Institution of Great Britain from 1887 till 1905. This institution had been keeping laboratories for physics and chemistry and a lecture theater for presenting outcomes of scientific research to the public [7]. Here Michael Faraday had performed important experiments in electricity and magnetism. He established a tradition of presenting Friday evening lectures for the intellectuals and Christmas lectures for children. This tradition was handed down to Faraday's successor, John Tyndall. When the post that Tyndall resigned due to ill health was offered to Rayleigh, he welcomed the offer. The duty imposed upon Rayleigh amounted to 6 Saturday afternoon lectures for lay audiences and one Friday lecture for professionals before Easter.

Rayleigh poured considerable effort into preparing his public lectures and performed them effectively. The conditions for demonstration experiments were considered to include the followings; they should be performed indoors and provide the audience with some experience beyond common life, the experimental results should be visible at a distance and it should be possible to account for the phenomena clearly and easily on scientific principles. Rayleigh, a skillful and meticulous experimenter, fully satisfied those conditions in designing and performing experiments.

\section{Rayleigh's Acoustical Experiments in Demonstration}

The following table (Table 1) shows the subjects and numbers of Rayleigh's public lectures delivered at the Royal Institution. The lectures of 1878 were 
delivered before he was appointed as Professor at the Royal Institution and the second group in 1887 seems to have been carried out as replacement during Tyndall's illness or while the appointment was being processed [8]. Following optics, his second most favorite subject for public lectures was sound and vibration.

Between 1901 and 1902, Rayleigh searched for suitable demonstration experiments on sound and vibration that would be understandable and interest-spurring [9]. Forced vibration was one of the most perfect subjects. Rayleigh presumed that this experiment could show characteristic four phenomena concerning forced vibration; firstly, the frequency of the vibrator is independent of its original natural frequency but determined by the frequency of the applied force. Secondly, if the frequency of the external force is lower than that of the natural frequency of the vibrator, the phase of the vibrator is identical to that of the

Table 1. Subjects of Rayleigh's public lectures delivered at the Royal Institution Source: R. J. Strutt, Life of John William Strutt, pp. 234-235.

\begin{tabular}{|c|c|c|}
\hline Year & $\begin{array}{l}\text { number of } \\
\text { lectures }\end{array}$ & Subject \\
\hline 1878 & 4 & Color \\
\hline 1887 & 6 & Sound \\
\hline 1888 & 6 & Experimental Optics \\
\hline 1889 & 7 & $\begin{array}{c}\text { Experimental Optics } \\
\text { (Polarization: Wave Theory) }\end{array}$ \\
\hline 1890 & 7 & Electricity and Magnetism \\
\hline 1891 & 6 & Cohesion \\
\hline 1892 & 6 & Matter: Static state \& Kinetic state \\
\hline 1893 & 6 & Sound and Vibration \\
\hline 1894 & 6 & Light: Newton's Discoveries in Optics \\
\hline 1895 & 6 & Wave and Vibration \\
\hline 1896 & 6 & Light \\
\hline 1897 & 6 & Electricity and Electrical Vibration \\
\hline 1898 & 3 & Natural Philosophy \\
\hline 1899 & 7 & Mechanical Properties of Matter \\
\hline 1900 & 6 & Polarization \\
\hline 1901 & 6 & Sound and Vibration \\
\hline 1902 & 6 & Development in the Field of Electricity \\
\hline 1903 & 6 & Light: Its Origin and Nature \\
\hline 1904 & 6 & Stokes' Life and Research \\
\hline 1905 & 3 & Controversial Points in Optics \\
\hline
\end{tabular}

force. In the third place, if the frequency of the vibration of the force is greater than the natural frequency of the vibrator, the phase of the vibrator is contrary to that of the force. Finally, if the frequency of the force is close to that of the natural frequency of the vibrator, the vibration grows infinitely.

Rayleigh found that he could show all the phenomena using a suspended, rod-shaped magnet with a mirror attached midway along its length. (Figure 1) He could vibrate a rod-shaped magnet suspended from a string by bringing it close to an identical rod-shaped magnet revolving around the vertical axis by a hand-operated gear. He could have the audience see the vibration easily by a light ray reflected by the mirror to a measuring scale on the screen. He adjusted the angular velocity of the revolving magnet to a given frequency determined by the metronome, and modified the torsional tension of the suspending string so that the natural frequency of the suspended magnet might be 10 vibrations per minute.

To show the first, the second and the third phenomena, it was enough to set the frequency of the rotating magnet to 8 or $12 \mathrm{rpm}$. At either of these frequencies, the magnet suspended from the string, though its natural frequency was 10 vibrations a minute, vibrated with the rotational frequency of the rotating magnet. When the magnet revolved at $8 \mathrm{rpm}$, the suspended magnet oscillated in the same phase as the revolving magnet, but when it revolved at 12 rpm, the magnet in the opposite phase. To

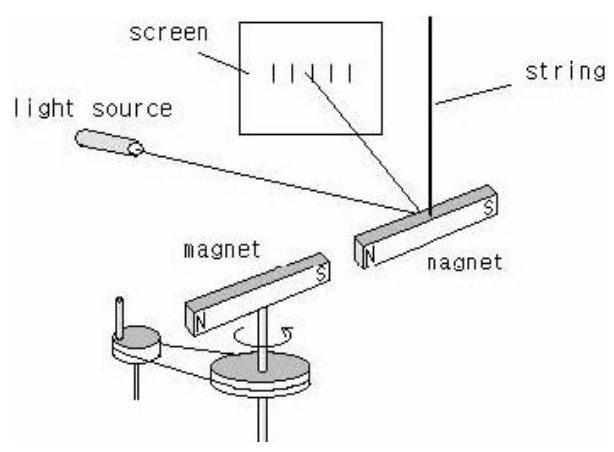

Fig. 1. Rayleigh's Forced Vibration Experiment. 
demonstrate the fourth phenomenon, it was enough to set the frequency of the revolving magnet to $10 \mathrm{rpm}$. Soon he could observe the amplitude of the vibration of the suspended magnet grow. This experiment was especially successful in that it contradicted common sense as well as provided curious visual effects. Rayleigh reduced the natural frequency of the revolving magnet to a low value so that everyone might recognize the vibration easily.

Melde's experiment with the vibration of a string was selected for Rayleigh's demonstration in 1901 [10]. This experiment consisted of vibrating a large tuning fork by intermittent electricity with a string attached to it. (Figure 2) Rayleigh connected a 3-meter long string to a tuning fork which was being electrically driven, and adjusted the tension of the string so that its vibration might be continued by the tuning fork. There were two distinctive patterns of the vibration of the string in this arrangement. When the direction of vibration of the tuning fork and the extension of the string were arranged orthogonal to each other, a forced vibration occurred so that the frequency of the string was identical with that of the tuning fork. Whereas when they were arranged parallel to each other, the string vibrated half as frequently as the tuning fork. Rayleigh's theoretical research into this had been already performed in the early 1880s [11]. While he was considering the experiment for demonstration,

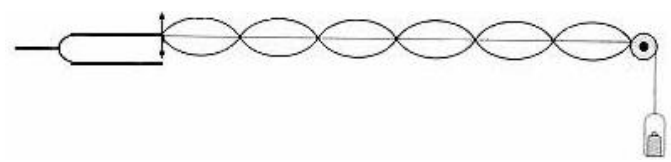

(a) When the vibration of the tuning fork and the extension of the string was orthogonal

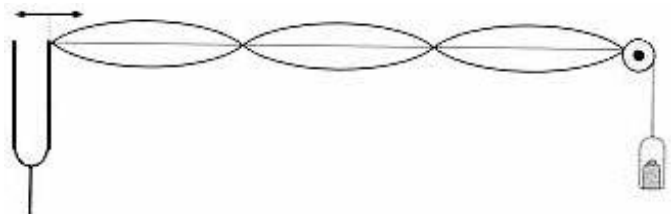

(b) When the vibration of the tuning fork and the extension of the string was parallel

Fig. 2. Melde's Experiment. it was one of the greatest difficulties that the audience could not observe the vibration visually. Rayleigh could cope with the problem by using intermittent illumination. In order to create an intermittent light source, Rayleigh employed an induction coil in the electrical circuit providing the tuning fork with intermittent electricity to make the electric magnet vibrate. The sparks were emitted whenever the prongs of the tuning fork were at their maximum displacement. When the frequency of the string was identical with that of the tuning fork, the string appeared to be fixed at one position. And when the frequency of the string was half as many as that of the tuning fork, the string appeared to be still at the two extreme positions. Thus Rayleigh could clearly show the audience that the two kinds of vibration in Melde's experiment are distinctively distinguished.

This experiment satisfied the conditions for a successful demonstration in that it provided the audience with unusual experiences where the arrangement of the string and the tuning fork determined the pattern of the vibration of the string and made the string appear to stand still. Rayleigh demonstrated his ability by explaining why those phenomena would occur and presented them visually to the audience.

Around this time another acoustical experiment was employed by Rayleigh for a public lecture whose subject was the diffraction and interference of sound. He acoustically represented Fresnel zones, which he called Huygens zones [12]. The Fresnel effect or the effect of Fresnel's zones is an optical phenomenon in which different zonal beams of wave while passing through a circular

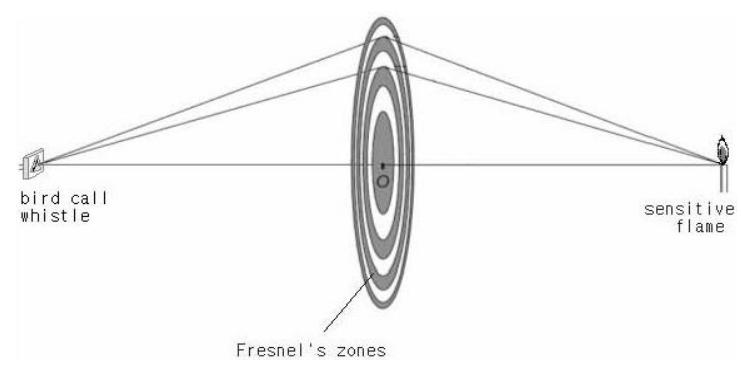

Fig. 3. Rayleigh's Fresnel's Zones Experiment. 
aperture interfere with each other. (Figure 3) For this demonstration, he needed to show the audience whether or not sound waves locally get to particular points. Since listening to sound was a private act of an individual, it had to be transformed to a public act of a group of people if it the demonstration was to be effective. Rayleigh accomplished this using the skills he had acquired through his research. He employed as the sound source the bird call whistle of which frequent use had been made in his experimental research since his invention of it in the 1870s.

He chose to use as the sound detector the sensitive flame, which also had been employed widely in his research. He placed a glass screen with a circular opening between the bird call whistle and the sensitive flame. By adjusting the radius of the opening and the wavelength of the bird call, and the distance between the sound source and the screen, he could establish the first zone (circle) and the second zone (ring) around the center of the opening of the glass screen. The sound beams passing through the first and the second zones interfered with each other destructively at some points. He could show that there was no sound at those points by the stillness of the flame. When one of the beams with the opposite phases was obstructed by placing a zonal obstacle on the screen, the sound that had been destroyed was recovered. And this fact was represented by the previously still flame beginning to flicker again when the obstacle was introduced. Thus Rayleigh could show that sound beams go through diffraction like light beams.

In this demonstration, the sensitive flame played an essential role by enabling the audience to ascertain the local presence of sound not by the ear but by the eye. His skill in using the sensitive flame to make sound visible had been acquired during a long series of experiments employing the flame. The sensitive flame contributed to satisfying the condition of the demonstration experiment by providing the public with unusual experiences. the audience was given a unique experience of 'seeing' sound. Rayleigh's demons tration experiments were examples of his skill and expertise in acoustics being utilized for improving public understanding of science.

\section{Conclusions}

All through his career, Rayleigh's acoustics was primarily pursued as science for its own sake. It did not need to be justified by its practicality. For him, acoustics provided a foundation for understanding the physical world mainly through vibration and wave. This was a unique characteristic of Rayleigh's acoustics in comparison with his predecessors. Even Helmholtz's acoustics, which had had a great influence on Rayleigh's, was justified by its practicality for music theory as we can see in his Tonempfindungen [13]. In earlier times, acoustical researches were usually carried out in relation with music. The main research objects centered on the pitch and the quality of tones. Noises were excluded from the main concern of acousticians, even in Rayleigh's acoustics. A new generation, less influenced by this tradition, focused more sharply on noises in the early twentieth century, opening a new era of practical acoustics [14].

As for Rayleigh, acoustics was worthy of being researched, independently of whether it had practical value. Even though Rayleigh did not aim his acoustics at practical application, he applied the expertise accumulated in his acoustical research to practical problems for improving human life. Public lectures opened up to him this opportunity. In solving practical problems, an expert's know-how, acquired from a long period of mathematical and experimental research into sound, could be used in various ways [15]. But his eagerness for understanding natural phenomena also led him to distinguish and to solve new research problems in acoustics.

Rayleigh's acoustical demonstration experiments 
involved the visualization of sonorous vibration in order to maximize the publication of private experiences concerning sound. In this process, Rayleigh utilized his experimental apparatus such as intermittent illumination, sensitive flames and birdcall whistles. Since the localized detection of aerial vibrations was difficult for the audience to share in, the enlarged visualization which Rayleigh adopted ingeniously was successful in providing interesting visual spectacles and spurring the scientific curiosity. By coping with the obstacles to the collective observation by meticulous and creative design of experiments, Rayleigh could optimize some acoustical experiments for demonstration.

\section{Acknowledgment}

This thesis was supported by the research funding of Youngsan University.

\section{References}

1. J. W. S. Rayleigh, The Theory of Sound, 2 vols. Dover, New York, 1945

2. D.-W. Kim, "The Emergence of the Cavendish School: An Early History of the Cavendish Laboratory, 1871-1900" Ph, D. Dissertation, Harvard University, 1991, pp. 67-73; J. C. Crowther, The Cavendish Laboratory 1874-1974, Macmillan, London and Basingstoke, 1974, pp. 88-102.

3. R. B. Lindsay, "Historical Introduction" in J. W. S. Rayleigh, The Theory of Sound, Dover, New York, 1945, vol. 1, pp. xxv.

4. M. W. Jackson, Harmonious Triads: Physicists, Musicians, and Instrument Makers in Nineteenth-Century Germany, MIT Press, Cambridge, 2006.

5. A. Thackray, "Natural Knowledge in Cultural Context: The Manchester Model," American Historical Review, vol. 79, pp. 672-709, 1974.

6. C. Taylor, The Art and Science of Lecture Demonstration, The Institute of Physics Publishing, London, 1995, pp. 29-40.

7. G. Caroe, The Royal Institution, John Murray, London, 1985.

8. R. J. Strutt, Life of John William Strutt, Third Baron Rayleigh, Edward Arnold \& Co., London, 1924, pp. 234.

9. Rayleigh, "Acoustical Notes VI," Philosophical Magazine, vol. 2, pp. 280-286, 1901.

10. Rayleigh, "Acoustical Notes VI," Philosophical Magazine, vol. 15, pp. 281-282, 1901.

11. Rayleigh, "On Maintained Vibration," Philosophical Magazine, vol. 2, pp. 231-235, 1883.

12. Rayleigh "Interference of Sound," Royal Institution Proceedings, vol. 17, pp. 3, 1902

13. J. H. Ku, "J.W. Strutt, Third Baron Rayleigh, The Theory of Sound, First Edition (1877-1878)" in I. Grattan-Guinness, ed. Landmark Writings in Western Mathematics 1640-1940, Elsevier, Amsterdam, 2005, pp. 588-589.

14. E. Thompson, The Soundscape of Modernity: Architectural Acoustics and the Culture of Listening in America, 19001933, MIT Press, Cambridge, 2002, Chapters 3-5.

15. J. H. Ku, "Accomplishments of Rayleigh's Experimental Research: Improvement of Instruments and Enhancement of Precision", (in Korean), Journal of the Acoustical Society of Korea, vol. 22, pp. 115-120, 2003.

\section{【Profile】}

-Ja Hyon Ku

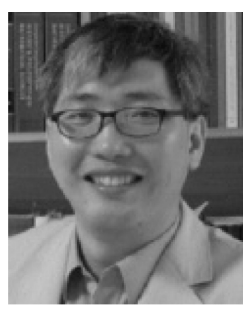

Received a B.S. in physics, an M.S. and a Ph D. in history of science from Seoul National University in 1989, 1995, and 2002, respectively. From 1998 to 2003, he was a part-time instructor at Seoul National University and other universities. From 2003, he has been a professor at Youngsan University, Korea. His main interest is the history of acoustics in the nineteenth century. 